\title{
A Study on the Current System of Vehicle Valuation in Sri Lanka
}

Dissertation Submitted to the University of Sri Jayewardenepura as a Partial Fulfilment for the Requirement of the Final Examination of the M.Sc. Real Estate Management and Valuation (Special) Degree.

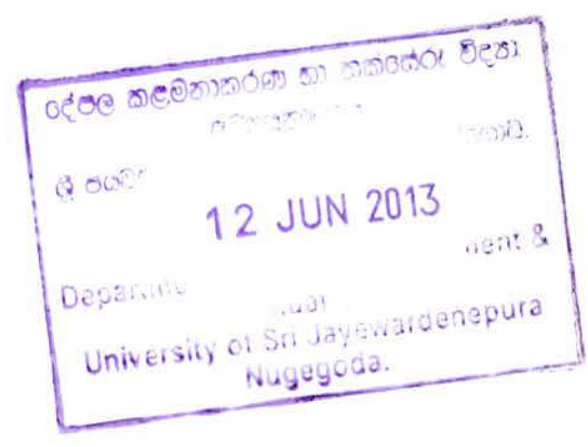

Name

Exam No.

Registration No.

Department

University

Date of Submission
P.P.D.N.Shayamali

86

REMV 3774

Department of Estate Management \& Valuation

University of Sri Jayewardenepura

$08 / 05 / 2013$ 
"The work described in this dissertation was carried out under the supervision of

Dr. U. Anura Kumara and any report on this has not been submitted in whole or in part to any university or any other institution for another degree/ examination or any other purpose"

Name

Exam No.

Registration No.

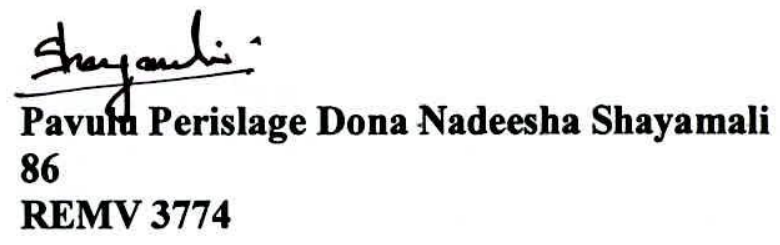

REMV 3774 
Here by, I certify that Miss. P.P.D.N.Shayamali REMV 3774 duly completed the research titled A Study on the Current System of Vehicle Valuation in Sri Lanka under my supervision and recommended to final submission.

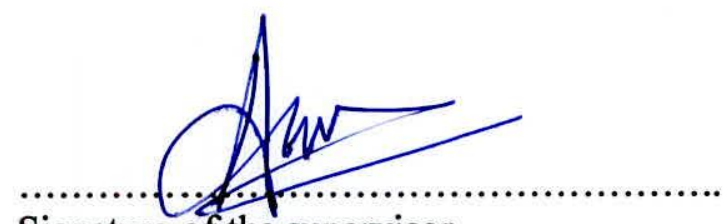

Signature of the supervisor

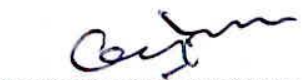

Signature of the first Examiner

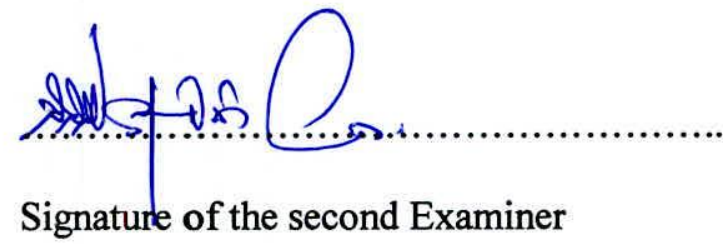

Signature of the official stamp of the head. 


\section{Acknowledgement}

I am deeply indebted to my supervisor senior lecturer Dr. U. Anura Kumara University of Sri Jayewardenepura who guided me in completing my research successfully, Prof. R.G.Aiyawansa, Mr. H.M.Premathilaka Mrs. Nishani Wickramarachchi, and Mrs. Padma Weerakoon senior lecturers, Msc in Real Estate Management \& Valuation Degree Program whose help, stimulating suggestions and guiding me during the course of the research and assisted me in preparing my research report.

Further, I do appreciate the valuable assistance given Mr.S.P.Weerarathne (former Deputy Chief Valuer of the Valuation Department, Mr. Isara Ariyarathna Risk Engineer - Technical of the Sri Lanka Insurance Cooperation. assisting me by providing me with the necessary advices and the relevant information to make this report a success.

A special appreciation deserved to Mr. Cecil Hilrey visiting lecturer of the Open University and also to my Father P.P.D.F. Appuhamy and my Mother J.J. Hapuarachchi who volunteered in assisting me to produce this report.

No doubt, I do owe big salute to all my colleagues who devoted their golden time by supporting us in every possible way to convert our effort in to a reality.

Shayamali P.P.D.N.

Msc Student.

08/05/2013 


\begin{abstract}
This research is a study of current system of vehicle valuation in Sri Lanka. The purpose of the research is to investigate the prevailing process of vehicle valuation in Sri Lankan economy and the areas related to the issue such as the function of the system, special features, specialties and weaknesses identified in the existing system and develop a novel model. Further it is intended for the identification of any possibility of application of real estate valuation methods for vehicle valuation.

The research is based on a survey results the questionnaires are used to collect the necessary data to address the issues in an original manner. Eighty actively practiced vehicle valuers in the current system taken as the population and the thirty of them taken as the sample size for testing the value variation. The findings of the study and also the value variation of individual valuers are analyzed using inferential statistical analysis and tested hypothesis. Further it is a descriptive analysis which enables us to address in the issues in the prevailing system. For the next analysis 1500 reported motor vehicle valuation in the Colombo metro branch is taken as the population for the testing the novel model fifty valuations taken as the sample size to validate the novel model. This novel model is expected to be practical and user friendly. To achieve the above objective several selected approaches are applied in the system. The vehicle valuation calculator has been tested with the samples of professionals' valuations.
\end{abstract}

As per the recommendations vehicles valuer in the private valuation sector should follow a set of rules and of these entry requirements to enter into the field. This may in support of the enhancement of ethics, norms, value of vehicle evaluation as a recognized sound position. This may further help to maintain uniformity in the industry. This may discourage biased valuation. It is observed that there are cases in which vehicles are either overvalued or undervalued. The use of data base on previous records will definitely make profession more objective than subjective. It would be useful for future references. Technically overestimation and underestimation could be avoided. A list of past data of a particular vehicle will be unarguably in support of the process of vehicle evaluation it may enhance accuracy and faith. It may assist the decision making parties to form an opinion of a vehicle with confidence. A list of recent market value of identical properties may give a clear vision of the kind of market. It will demarcate the upper and lower limits and the variation of a property and the proper basis of valuation is counted. This makes the businesses transparent and gives the businesses an identity.

For the future research areas is research on the effect of another factor and finding in depreciation rate in replacement cost. It is the application of appropriate capitalization rate of vehicle into invested vehicles so as to build the better relationship between income and value, in order to arrive at a realistic market value of the property. So another research is the application of direct capitalization method into income approach. 


\title{
Table of Content
}

\author{
Acknowledgement \\ Abstract \\ Table of Content \\ List of Tables \\ List of Figures
}

Contents

CHAPTER ONE - Introduction

1.1. Introduction

1.2. Back ground of the problem

1.3. Statement of the problem

1.4. Objectives of the study

1.5. Significance of the study

1.6. Limitations

1.7. Structure of the thesis

1.8. Summary

CHAPTER TWO - Literature Review

2.1 Introduction

2.2 Theoretical back ground of valuation.

2.3 Valuation approaches

2.3.1 The Cost Approach

2.3.2 The Direct Comparison Approach 16

$\begin{array}{ll}\text { 2.3.3 The Income Approach } & 17\end{array}$

2.4 Automobile Valuation 20

2.5 Legal aspects of automobile valuation 21

$\begin{array}{ll}2.6 & \text { Market Development } \\ 2.7\end{array}$

$\begin{array}{lll}2.7 & \text { Summary } & 27\end{array}$

CHAPTER THREE- Research Design \& Research Methodology 28

3.1 Introduction 28

3.2 Problem of Research 28

3.3 Research Questions 29

3.4 Research Design 29

$\begin{array}{ll}3.5 & \text { Methodology } \\ 3.6 & 30\end{array}$

3.6 Method of data collection $\quad 30$

$\begin{array}{lll}3.7 & \text { Analysis of data } & 32\end{array}$

$\begin{array}{lll}3.8 & \text { Population and sample } & 32\end{array}$

3.9 Steps of developing novel model $\quad 33$

3.10 Summary 33 
4 CHAPTER FOUR - Current vehicle valuation system in Sri Lanka 35

4.1. Introduction $\quad 35$

4.2. Current system of vehicle valuation 35

$\begin{array}{lll}4.3 & \text { Issues and weakness of vehicle valuation } & 38\end{array}$

$\begin{array}{lll}4.4 & \text { Value variation in vehicle valuation } & 41\end{array}$

4.5. Factors affecting to the valuation reports 60

4.6. Recommendations on improving valuation accuracy from current valuers 62

$\begin{array}{lll}\text { 4.7. } & \text { Summary } & 63\end{array}$

5 CHAPTER FIVE- Applicability of real estate valuation approaches for vehicle valuation.

5.1 Introduction

5.2. Application of cost approach $\quad 64$

$\begin{array}{lll}5.3 & \text { Application of income approach } & 68\end{array}$

$\begin{array}{ll}5.4 & \text { Application of direct comparison approach. }\end{array}$

$\begin{array}{lll}\text { 5.5. Summary } & 77\end{array}$

6 CHAPTER SIX- Novel model for vehicle valuation. $\quad 79$

6.1. Introduction $\quad 79$

6.2 Details of subject vehicle to be valued 80

6.3. Validity and Reliability 89

$\begin{array}{ll}\text { 6.5. Summary } & 102\end{array}$

7 CHAPTER SEVEN - Conclusions and recommendations 103

$\begin{array}{ll}\text { 7.1. Introduction } & 103\end{array}$

7.2. Conclusion 105

7.3. Recommendation 108

7.4. Future Research Areas 109

$\begin{array}{ll}\text { References } & 110\end{array}$

Annexes

Questionnaire 01

Questionnaire 02

List of Leasing Association Valuers 


\section{List of Table}

Table

2.1 Capitalization rate of property

4.1 Details of a vehicle

$\begin{array}{ll}4.2 & \text { Value variation of vehicle } \\ 4.3\end{array}$

4.3 Statistical Analysis Using SPSS $\quad 46$

$\begin{array}{lll}4.4 & \text { Test of Normality } & 57\end{array}$

$\begin{array}{lll}4.5 & \text { Test Statistics } & 58\end{array}$

4.6 Comparing Valuers and Stakeholders view point 60

5.1 Comparison of depreciation factor 65

5.2 Returns of vehicle and the real estate $\quad 75$

\begin{tabular}{ll}
5.3 & Comparison of vehicle prices \\
\hline
\end{tabular}

$\begin{array}{ll}6.1 & \text { Weighted Component of Vehicle } \\ 67\end{array}$

6.2. Weight as Condition $\quad 89$

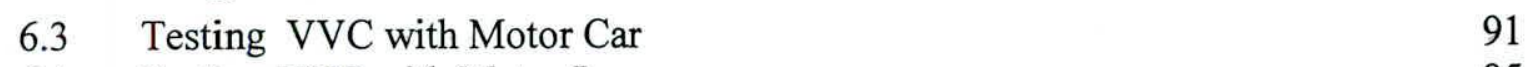

6.4 Testing VVC with Motor Lorry 95

\section{List of Figures}

Figure

2.1 Custom duty on vehicles $\quad 22$

2.2 Custom Depreciation factor for vehicles 23

2.3 Cost Contributors to retails price in vehicles 25

3.1 Flow Chart of Research Methodology 34

$\begin{array}{lll}4.1 & \text { Reason of selecting valuation approaches } & 37\end{array}$

4.2 Satisfaction of stakeholders 38

4.3 Reason for dis-satisfaction of professional valuers 39

4.4 Reason for selection of valuers 39

4.5 Accuracy level of valuation $\quad 40$

4.6 Uniformity of valuation 41

4.7 Value variation of Lanka Asok Leyland- light motor lorry 47

4.8 Value variation of TATA motor lorry $\quad 48$

4.9 Value variation of Mercedes Benz motor car 49

4.10 Value variation of Toyota dual purpose van 50

4.11 Value variation of Nissan dual purpose van 51

4.12 Value variation of Hybrid Vehicle 52

4.13 Value variation of Toyota Allion 53

4.14 Value variation of Mazda Bongo $\quad 54$

4.15 Value variation of Suzuki Shift 55

4.16 Value variation of Hi Ace, Regius Ace 56

4.17 Professional errors in valuation reports $\quad 59$

4.18 Professional errors in stakeholders point of view 59

4.19 Factors affecting to the valuation reports 61

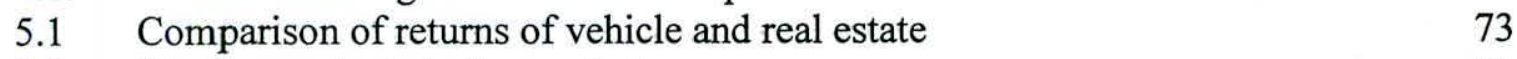

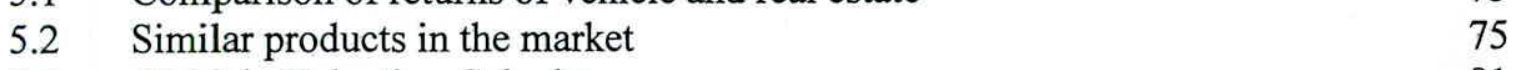

$\begin{array}{lll}6.1 & \text { Vehicle Valuation Calculator } & 81\end{array}$

$\begin{array}{lll}6.2 & \text { Options of VVC } & 81\end{array}$ 
6.3 Options of VVC - Comparison price

6.4 Market Analyses for Recondition Vehicles $\quad 82$

6.5 Adjusted prices for Brand New Vehicles 83

6.6 Vehicle Valuation Calculator $\quad 84$

6.7 Technical Valuation $\quad 86$

6.8 Technical Weight in valuation $\quad 86$

6.9 Value of Vehicles Using Existing Method 93

6.10 Value of vehicle using vehicle valuation calculator 94

6.11 Value of Vehicle Comparison using both methods 100 


\section{CHAPTER ONE}

\section{Introduction}

\subsection{Introduction}

The focus of this study is to investigate the prevailing process of vehicle valuation in Sri Lankan economy and the areas related to the issue such as the function of the system, special features, specialties and weaknesses identified in the existing system. In the field of commercial trade, valuation is a must. It is essential both for trade and financial need in the social and economic development. As the background of this study, the issues related to the vehicle valuation in Sri Lankan economy would be taken in to discussion and its importance and other factors related to it. In addition to that the general and specific objectives of research along with the limitation of the study will also be under discussion in the chapter to come.

\subsection{Background of the problem}

Despite the fact that Sri Lanka is a lower middle country in its present context, vehicles are no more considered to be as luxury items. With the development of the living standard of the modern man, a vehicle has been a part and parcel of daily life of the man similar to the basic requirements of the man such as food, shelter, clothes etc. For some people, a vehicle is a mode of investment where as for some others it is for social prestige. This has shown a remarkable development with the recent expansion of the road network under the development projects of the present government. With this rapid growth of the use of vehicle for domestic and commercial purposes, valuation of vehicles has earned much emphasis and has become an absolute necessity. 
During the past decade total number of vehicles has increased by $208.96 \%$. In 2002 it was $1,892,367$ and in 2010 it has increased up to 3,954,311. Further a significant increase in registration of new vehicles is seen in Sri Lanka, it is $316.96 \%$ over the past decade. It was 113,351 and in 2010 it has increased up to 359, 243(Motor Traffic Department, 2010)

This demand has been to some extent, due to the taxes introduced by the government. As a result of that specially in a developing country like Sri Lanka a considerable amount of general public is not in a position to afford a vehicle. In a country like Sri Lanka where the low per capita income of a person makes a purchase of a vehicle for an average citizen s challenge. People are compelled to seek assistance from financial institutions. Thus, the assistance of financial institutions plays a crucial role in the purchasing a vehicle and in this context valuation of vehicle is significantly important.

Valuation is a process of finding the present market value of future income flow of an interest of a property, using past information. The system is both a replica and a reflect of valuation activity and as such, it replicates a judgment pooled together, skills, various attitudes, viewpoints, procedures and methods that relate to subject of value.

To determine the value of a property the valuer integrates collective data and information and analyzes them for the appropriate approaches for application. Value is an appraiser's opinion - judgment from the gathered information - it depends on the valuer's skills, knowledge, and experience furthermore proper data analysis methods are very significant to make a decision in an appraisal of a property.

\subsection{Statement of the problem}

Due to the high volume of transaction, valuation requirement is essential for the purposes of finance sales and assets. Due to the lack of centralized system for automobile valuation in the current system and also a governing body vehicle valuation in Sri Lanka has been more subjective than objective. Most of the private valuers and institutional valuers are not responsible for auditing, accountability and 
standardization. In addition to that technical updates and improvements are not well matched with the development in the industry.

Thus the problem addressed here is what the Issues here are, what the weaknesses are, what the inherent characteristics when engaged in a study of the prevailing system of vehicle valuation in Sri lanka to quantify the areas mentioned in the objectives that have been given below.

\subsection{Aim of the study}

The aim of the research is to study the current system of vehicle valuation in Sri Lanka and develop a novel model for the vehicle valuation

\subsubsection{Specific objectives}

- To identify the issues of the current vehicle valuation system in Sri Lanka - To identify the possibility of the application of the real estate valuation methods for vehicle valuation

- To develop a model which realistically reflects the valuation of vehicles.

\subsection{Significance of the study}

The significance of the study is to identify accuracy and variation of auto mobile valuation in the prevailing system of automobiles valuation in Sri Lanka. Valuation in Sri Lanka has been a subjective study. As a result of that valuation differs from person to person and location to location. The percentage of variation of this current valuation process is to be assessed. It is expressed to obtain a precise valuation with the novel approach known as the valuation calculator.

At present, a common valuation system tool which is trustworthy and acceptable is not in use. With the introduction of this valuation calculator this process is expected to be scientific and systematic. 
Further this study assesses the practical use of current theoretical real estate approaches in automotive valuation. Since the date of the product of a vehicle, average market value may varies from the value suggested by theories. This is also one of the factors to be identified. The analysis of value variation on vehicle based on a time line enables the investor to obtain optimum period of return for investment purposes. At the same time there can be seen a simultaneous increase the vehicle and the need of vehicle valuation. This research assists this in order to obtain an accurate valuation report within a short period of time.

In Sri Lanka with the expansion of human needs and services the demand for auto mobiles has also periodically increased for the purposes such as transportation, investment social status, logistics etc. According to the transport statistics given by Department of Motor Transport there are 164 motor vehicles per 100 person in the world and 25 motor vehicles per 100 persons in Sri Lanka.

Automobiles play an indispensable role in the areas of logistics, businesses, investment and trade. The role of the vehicle in a life of the man is evident from the increasement the registration of vehicles. As statistics of the department of motor traffic in 2009 reveals the registration of vehicle has been increased from 204,075 to 339,243 towards the end of the 2010 . This records a growth of 340,000 of vehicles for the year 2010. These means that both the supply of the vehicles to the market as well as the purchase of the vehicles too have been increased.

In Sri Lankan Market both brand new and used vehicles are sold. There is a noticeable increasement in the market shares of vehicles. Due to that reason there is an urgent need for a real valuation mechanism for a vehicle. Further this study in support of many other related purposes

- A proper identification of the vehicle, comprehension of the legal aspect, the date of the real market valuation in accordance with legal aspect, chassis number are some of the salient factors in sales / Purchase.

- For accounting purposes such as calculation of final accounts as an assets in the balance sheet this evaluation system may be practical 
- At the same time for the official duties of the custom taxes proper valuation is a must.

- $\quad$ To get a loan from a financial institution leasing company, mortgage, etc. proper identification of a vehicle is important.

- Insurance companies may to find it convent to make their services efficient when they were able to value a vehicle based on a scientific method.

It is the responsibility of a valuer to realize why valuation is required. Today in Sri Lanka valuation of a vehicle is in consistent due to the application of various methods and approaches. So there is not a sound methodology for the process of vehicle valuation. In vehicle market price is a variable factor. A price means the amount the potential seller expects to have for a vehicle, the potential buyer ready to spend in their transaction.

This method makes the process of vehicle valuation more systematic, scientific, objective and practical. Then those who engaged in this business are expected to be more competent in their profession to secure accuracy in their valuation. Further this may inculcate norms in the field of vehicle valuation.

\subsection{Limitations}

Due to constraints in the field of vehicle valuation, there are limitations. One such is the avoidance of classes of vehicle such as motor cycles, three wheelers and land vehicles towards the development of this methodology.

Valuation is done only through the specification provided by the manufactures. Additional or extra modification conditions have been excluded in this valuation criteria.

Geographical dispersion is also another neglected factor in value variation. Further the sample selected is to be considered as a representative sample as only 50 vehicles from the metro region of government valuation department have been selected for the research sample for testing novel model. 


\subsection{Structure of the thesis}

The First Chapter of this thesis is an introduction to the vehicle valuation and it emphasizes the significance of the study. The index presents chapter wise organization of the thesis. The purpose of the second chapter is to design the concept, theoretical models, literal review etc. To be more sound there is an extensive literary review basically collected from the existing literature on theoretical background of valuation, Valuation approaches, Automobile valuation, , Legal aspect of automobile valuation, measurements and the application, classification of the auto mobiles, Market Development etc.

The third chapter discusses the conceptualization of Research problem and raises a number of research questions. Further it indicates the methodology and the steps that have been taken to achieve the objectives, population, and sample analysis of market value of vehicle addressing to the each research question in detail.

The forth chapter indicates data collected and analytically evaluated in order to arrive at the set goals of the research. In addition to that, the methodology employed for the collection of fact, organization fact analytical study of fact evaluation of fact for final assessment are also included. This chapter covers objective of the issues, and the weaknesses in the current vehicle valuation system.

The fifth chapter for the practical applicabilities of the suggested model is in contrast to the theoretical approaches that are seen in the current vehicle valuation field.

The intention of the fifth chapter is to investigate how far it is practical when the theories of real estate valuation are used to vehicle valuation. The sixth chapter is intended for the model for the vehicle valuation and has a thorough discussion over the selected model from the improvements steps statistical analysis etc... used for the development of the model. The final chapter presents in the foam of a summery. The date of previous analyzed recommendation derived etc with much emphasis of the major concern of the study. 